\title{
Microarray-based determination of anti-inflammatory genes targeted by 6-(methylsulfinyl)hexyl isothiocyanate in macrophages
}

\author{
JIHUA CHEN $^{1}$, TAKUHIRO UTO ${ }^{1,4}$, SHUNSUKE TANIGAWA ${ }^{1}$, \\ TOMEO YAMADA-KATO ${ }^{3}$, MAKOTO FUJII ${ }^{1,2}$ and DE-XING HOU ${ }^{1,2}$ \\ ${ }^{1}$ Course of Biological Science and Technology, United Graduate School of Agricultural Sciences, and \\ ${ }^{2}$ Department of Biochemical Science and Technology, Faculty of Agriculture, Kagoshima University, \\ Kagoshima 890-0065; ${ }^{3}$ Kinjirushi Co., Ltd., Nagoya City, Aichi 454-8526, Japan
}

Received August 6, 2009; Accepted September 29, 2009

DOI: 10.3892/etm_00000006

\begin{abstract}
Methylsulfinyl)hexyl isothiocyanate (6-MSITC) is a bioactive ingredient of wasabi [Wasabia japonica (Miq.) Matsumura], which is a popular pungent spice of Japan. To evaluate the anti-inflammatory function and underlying genes targeted by 6-MSITC, gene expression profiling through DNA microarray was performed in mouse macrophages. Among 22,050 oligonucleotides, the expression levels of 406 genes were increased by $\geq 3$-fold in lipopolysaccharide (LPS)-activated RAW264 cells, 238 gene signals of which were attenuated by 6-MSITC ( $\geq 2$-fold). Expression levels of 717 genes were decreased by $\geq 3$-fold in LPS-activated cells, of which 336 gene signals were restored by 6-MSITC ( $\geq 2$-fold). Utilizing group analysis, 206 genes affected by 6-MSITC with a $\geq 2$-fold change were classified into 35 categories relating to biological processes (81), molecular functions (108) and
\end{abstract}

Correspondence to: Dr De-Xing Hou, Department of Biochemical Science and Technology, Faculty of Agriculture, Kagoshima University, Korimoto 1-21-24, Kagoshima 890-0065, Japan

E-mail: hou@chem.agri.kagoshima-u.ac.jp

Present address: ${ }^{4}$ Department of Pharmacognosy, Faculty of Pharmaceutical Sciences, Nagasaki International University, Nagasaki 859-3298, Japan

Abbreviations: 6-MSITC, 6-(methylsulfinyl)hexyl isothiocyanate; $\mathrm{CCL}$, chemokine (C-C motif) ligand; COX-2, cyclooxygenase-2; CX3CL, chemokine (C-X3-C motif) ligand; IKK, inhibitor of $\kappa \mathrm{B}$ kinase; iNOS, inducible nitric oxide synthase; IPA, Ingenuity pathways analysis; IRAK, interleukin-1 receptor-associated kinase; MyD88, myeloid differentiation factor 88; PGE2, prostaglandin E synthase 2; PTGS2, prostaglandin-endoperoxide synthase 2; TIR, toll/interleukin (IL)-1 receptor; TLR, toll-like receptor; TRAF6, Tnf receptor-associated factor 6; TRAM, TRIF-related adaptor molecule; TRIF, TIR domain containing adaptor inducing interferon (IFN)- $\beta$

Key words: wasabi, 6-(methylsulfinyl)hexyl isothiocyanate, DNA microarray, macrophage signaling pathways (17). The genes were further categorized as 'defense, inflammatory response, cytokine activities and receptor activities' and some were confirmed by real-time polymerase chain reaction. Ingenuity pathway analysis further revealed that wasabi 6-MSITC regulated the relevant networks of chemokines, interleukins and interferons to exert its antiinflammatory function.

\section{Introduction}

Wasabi [Wasabia japonica (Miq.) Matsumura], called Japanese horseradish, is a member of the Brassicaceae family of vegetables. Its rhizome is a very popular pungent spice in Japan. Several studies have shown that wasabi has multiple biological activities, such as anti-microbial activity (1), inhibition of platelet aggregation (2) and the suppression of $N$-methyl- $N$ '-nitro- $N$-nitrosoguanidine (MNNG)-induced rat gastric carcinogenesis (3). Accumulated data reveal that a series of allyl isothiocyanates are present in its rhizome as active compounds (4) of which 6-(methylsulfinyl)hexyl isothiocyanate (6-MSITC or 6-MITC in previous reports) is a major allyl isothiocyanate (5). Our group recently reported that 6-MSITC inhibits lipopolysaccharide (LPS)-induced expression of cyclooxygenase-2 (COX-2) (6) and inducible nitric oxide synthase (iNOS) (7). These data suggest that 6-MSITC may have potential as an anti-inflammatory agent.

Inflammation is essential for defense against bacterial infection. Expression of inflammatory cytokines, chemokines and other mediators are involved in inflammatory processes (8). Although recognition of invading pathogens by host cells initiates the binding of specific cellular receptors to pathogen molecules with distinct patterns (9), toll-like receptors (TLRs) are the major pattern-recognition receptors. In particular, inflammation caused by LPS is one of the most extensively studied cases (10). LPS liberated from gram-negative bacteria associates with LPS binding protein, an acute phase protein present in the bloodstream and subsequently binds to CD14 antigen (CD14), a glycosylphosphatidylinositol-linked protein expressed on the cell surface of phagocytes. LPS is then transferred to MD-2, which associates with the extracellular portion of toll-like receptor 4 (TLR4), followed by 
oligomerization of TLR4, a key molecule of LPS signaling $(11,12)$. TLR4 signaling promptly induces potent innate immune responses through adaptor molecules, such as myeloid differentiation factor 88 (MyD88), toll/interleukin (IL)-1 receptor (TIR) domain containing adaptor protein, TRIFrelated adaptor molecule (TRAM) and TIR domain containing adaptor inducing interferon- $\beta$ (TRIF) to activate intracellular signaling pathways involving interleukin-1 receptor-associated kinase (IRAK), Tnf receptor-associated factor 6 (TRAF6), inhibitor of $\kappa \mathrm{B}$ kinase (IKK) and mitogen-activated protein kinase (MAPK) $(13,14)$. These signaling pathways ultimately stimulate transcription factors, nuclear factor $\kappa \mathrm{B}(\mathrm{NF}-\kappa \mathrm{B})$, activator protein 1 (AP-1) and interferon regulatory factors to induce antibacterial and antiviral responses including the induction of tumor necrosis factor (TNF), interleukin-1 (IL1) and interleukin-6 (IL6) (15).

To evaluate the anti-inflammatory function and underlying genes targeted by wasabi 6-MSITC, we used oligonucleotide DNA microarray to investigate the effects of 6-MSITC on genome-wide gene expression in an inflammatory cell model, murine macrophage-like RAW264. Furthermore, we explored the molecular interaction networks from gene expression data, using Ingenuity pathway analysis (IPA) software. These data revealed a molecular basis for the anti-inflammatory activity of 6-MSITC.

\section{Materials and methods}

Materials and cell culture. 6-MSITC was purified by reversephase HPLC to $>99 \%$, and dissolved in dimethyl sulfoxide for cell culture (DMSO final concentration, 0.2\%). LPS (Escherichia coli serotype 055:B5) and other reagents used in the chemical analysis were purchased from Sigma Chemical. Murine macrophage-like RAW264 cells were obtained from Riken BioResource Center Cell Bank, Japan (cell no. $\mathrm{RCB} 0535)$ and cultured at $37^{\circ} \mathrm{C}$ in a $5 \% \mathrm{CO}_{2}$ atmosphere in Dulbecco's modified Eagle's medium containing $10 \%$ fetal bovine serum.

RNA preparation and microarray hybridization. RAW264.7 cells were pretreated with or without 6-MSITC for $30 \mathrm{~min}$ and then exposed to $40 \mathrm{ng} / \mathrm{ml}$ LPS for $6 \mathrm{~h}$. Total RNA was extracted using Qiagen ${ }^{\mathrm{TM}}$ RNeasy mini kit (Valencia, CA) following the manufacturer's protocol. The RNA quantity was assessed using an Agilent 2100 bioanalyzer (Palo Alto, CA). Total RNA (500 ng) was amplified at $40^{\circ} \mathrm{C}$ for $2 \mathrm{~h}$ by the Agilent low RNA input fluorescent linear amplification kit following the manufacturer's protocol. cRNAs were labeled at $40^{\circ} \mathrm{C}$ for $2 \mathrm{~h}$ with cyanine 5 (Cy5) for samples and with cyanine $3(\mathrm{Cy} 3)$ for the universal mouse reference RNA (Agilent Technologies). After the amplification and labeling, the yields and dye incorporation efficiencies were determined using a spectrophotometer. Agilent mouse 22,050 oligonucleotide microarrays were used for this study following Agilent microarray processing protocol. Briefly, Cy3-labeled samples and Cy5-labeled references were mixed and incubated with an Agilent microarray slide for $17 \mathrm{~h}$ using an Agilent in situ hybridization kit. After washing with stabilization and drying solution (Agilent Technologies), microarray signals were scanned in an Agilent model G2505A microarray scanner.
Table I. Number of genes that are regulated by 6-MSITC.

\begin{tabular}{lrc}
\hline Fold change & LPS/CTL & (6-MSITC+LPS)/LPS \\
\hline$\geq 9$ & 90 & 74 \\
$\geq 6$ to $<9$ & 85 & 59 \\
$\geq 3$ to $<6$ & 231 & 105 \\
Subtotal & 406 & 238 \\
$>-6$ to $\leq-3$ & 664 & 321 \\
$>-9$ to $\leq-6$ & 26 & 12 \\
$\leq-9$ & 7 & 3 \\
Subtotal & 717 & 336 \\
Total & 1123 & 574 \\
\hline
\end{tabular}

CTL, control; LPS, lipopolysaccharide.

Data analysis. Images were processed using Agilent Feature Extraction software, which provides normalized $\mathrm{Cy} 3$ and Cy5 channel intensity values for each spot on an array (for a detailed description of the Agilent Feature Extraction software and the algorithms, see the Agilent Feature Extraction User's Manual). The selected genes were further classified into the biological process, molecular function and signaling pathway by the Gene Ontology software (http://www.geneontology. $\operatorname{org} /)$.

Reverse transcription and real-time PCR. The primers used in the present study have been described in previous studies (16). The primers for IL1 $\alpha$, IL1 $\beta$, IL6, IFI1 and IFI47 were designed according to the NCBI sequence database using the software Primer3 (16). The primers for TNF (17), COX-2 (20), CCL22 (18) and PTGS2 (19) have been described previously. Reverse transcription and real-time PCR were performed with DyNAmo $^{\text {TM }}$ SYBR $^{\circledR}$ Green 2-Step qRT-PCR Kit (Finnzymes Oy., Espoo, Finland) according to the manufacturer's manual. Briefly, RNA (200 ng) was reversed to cRNA using Oligo $\mathrm{dT}$ and M-MuLV RNase at $37^{\circ} \mathrm{C}$ for $30 \mathrm{~min}$, and the reaction was then terminated at $85^{\circ} \mathrm{C}$ for $5 \mathrm{~min}$. Quantitative PCR was performed with the Roter-Gene-3000AKAA (Corbett Research) in triplicates using the standard curve. The Tm-value of PCR was determined according to each primer sequence (https://www.finnzymes.fi/tm.determination.html). Each PCR reaction contained $250 \mathrm{ng}$ of reverse transcripts, $75 \mathrm{ng}$ of each primer and $10 \mu \mathrm{l}$ Master mix (Finnzymes Oy.). The thermal cycling condition was held at $95^{\circ} \mathrm{C}$ for $15 \mathrm{~min}$ followed by 55 cycles of $30 \mathrm{sec}$ at $94^{\circ} \mathrm{C}, 30 \mathrm{sec}$ at Tm-value (16) and $30 \mathrm{sec}$ at $72^{\circ} \mathrm{C}$. The result was represented by the relative expression level normalized with control cells.

Pathway analysis and network generation. Gene accession numbers, the fold change upon 6-MSTIC treatment vs. the control cells, and the t-test P-value were imported into the IPA software. IPA was carried out with $\mathrm{P}<0.002$ as the cutoff point. The genes were categorized according to the molecular functions using the software. The identified genes were also mapped to genetic networks in the IPA database and ranked by a score that denotes the probability that a collection of 
Table II. Classification of genes targeted by 6-MSITC in LPSactivated macrophages.

\begin{tabular}{|c|c|c|c|}
\hline Category & CTL & LPS & $\begin{array}{l}(\mathrm{M}+\mathrm{LPS}) / \\
\mathrm{LPS}\end{array}$ \\
\hline \multicolumn{4}{|l|}{ Biological process } \\
\hline Apoptosis & 192 & 17 & 9 \\
\hline Carbohydrate metabolism & 107 & 4 & 2 \\
\hline Cell adhesion & 289 & 5 & 2 \\
\hline Cell cycle & 247 & 3 & 2 \\
\hline Cell proliferation & 69 & 5 & 2 \\
\hline Defense & 121 & 4 & 4 \\
\hline Signal transduction & 546 & 29 & 21 \\
\hline Transport & 1001 & 10 & 7 \\
\hline Lipid metabolic process & 125 & 1 & 1 \\
\hline Inflammatory response & 88 & 16 & 13 \\
\hline Cytokine activity & 139 & 23 & 18 \\
\hline \multicolumn{4}{|l|}{ Molecular function } \\
\hline $\begin{array}{l}\text { Cell adhesion } \\
\text { molecule activity }\end{array}$ & 289 & 5 & 2 \\
\hline Cytoskeletal protein binding & 25 & 1 & 0 \\
\hline Defense response & 121 & 4 & 4 \\
\hline Hydrolase activity & 977 & 27 & 17 \\
\hline Ion channel activity & 233 & 1 & 0 \\
\hline Kinase activity & 621 & 20 & 9 \\
\hline Lyase activity & 78 & 2 & 1 \\
\hline Protein ubiquitination & 120 & 2 & 1 \\
\hline Nucleic acid binding & 394 & 7 & 5 \\
\hline Oxidoreductase activity & 384 & 4 & 3 \\
\hline Receptor activity & 1513 & 38 & 21 \\
\hline Signal transduction & 546 & 29 & 21 \\
\hline Transcription factor activity & 500 & 14 & 10 \\
\hline Transferase activity & 1015 & 25 & 13 \\
\hline Transporter activity & 142 & 2 & 1 \\
\hline \multicolumn{4}{|l|}{ Pathway } \\
\hline Angiogenesis & 63 & 2 & 2 \\
\hline Apoptosis & 192 & 17 & 9 \\
\hline B-cell activation & 8 & 3 & 3 \\
\hline Blood coagulation & 42 & 1 & 0 \\
\hline Cell adhesion & 289 & 5 & 2 \\
\hline $\begin{array}{l}\text { Cytokine and chemokine- } \\
\text { mediated signaling pathway }\end{array}$ & 21 & 3 & 1 \\
\hline $\begin{array}{l}\text { Integrin-mediated } \\
\text { signaling pathway }\end{array}$ & 62 & 2 & 0 \\
\hline JAK-STAT cascade & 11 & 1 & 0 \\
\hline
\end{tabular}

CTL, control; LPS, lipopolysaccharide; M, 6-MITC; LPS/CTL, >3-fold; (M+LPS)/LPS, >2-fold.

genes equal to or greater than the number in a network could be achieved by chance alone. The genetic network analysis focuses on the functional relationships that are present in the literature to create a network of genes with similar functions and recorded interactions. A network pathway is a graphical
Table III. List of genes targeted by 6-MSITC in categories of 'defense, inflammatory response, cytokine activity and receptor activity'.

\begin{tabular}{|c|c|c|c|}
\hline Gene & Accession no. & LPS/CTL & $(\mathrm{M}+\mathrm{LPS}) / \mathrm{CTL}$ \\
\hline CCL12 & NM_011331 & 8.48 & 2.83 \\
\hline CCL17 & NM_011332 & 17.64 & 3.63 \\
\hline CCL2 & NM_011333 & 22.01 & 1.79 \\
\hline CCL22 & NM_009137 & 6.79 & 0.51 \\
\hline CCL4 & NM_013652 & 91.36 & 40.87 \\
\hline CCL5 & NM_013653 & 29.18 & 2.14 \\
\hline CCL7 & NM_013654 & 302.69 & 1.34 \\
\hline CCL9 & NM_011338 & 4.51 & 1.34 \\
\hline CCR1 & NM_009912 & 7.94 & 2.51 \\
\hline CCRL2 & NM_017466 & 28.93 & 2.04 \\
\hline CD300le & NM_172050 & 8.24 & 0.64 \\
\hline CD86 & NM_019388 & 3.70 & 1.22 \\
\hline $\mathrm{COX}-2$ & AF344876 & 5.85 & 1.78 \\
\hline CSF2 & NM_009969 & 124.48 & 15.85 \\
\hline CX3CL1 & NM_009142 & 3.56 & 1.37 \\
\hline CXCL10 & NM_021274 & 63.04 & 1.13 \\
\hline ICOSL & NM_015790 & 3.68 & 1.59 \\
\hline IFI1 & NM_008326 & 3.97 & 0.64 \\
\hline IFI47 & NM_008330 & 2.71 & 1.27 \\
\hline IFNB1 & NM_010510 & 35.30 & 2.41 \\
\hline IL10 & NM_010548 & 10.80 & 1.08 \\
\hline IL1f6 & NM_019450 & 11.63 & 1.10 \\
\hline IL1rn & NM_031167 & 7.88 & 1.14 \\
\hline IL6 & NM_031168 & 718.90 & 53.26 \\
\hline IRAK2 & NM_172161 & 5.41 & 2.06 \\
\hline NFKBIZ & NM_030612 & 57.08 & 16.83 \\
\hline PTGS2 & NM_011198 & 416.00 & 142.40 \\
\hline PTGER2 & NM_008964 & 28.78 & 3.82 \\
\hline TLR1 & NM_030682 & 3.68 & 1.41 \\
\hline TNF & NM_013693 & 2.49 & 1.00 \\
\hline TNFRSF5 & NM_011611 & 6.81 & 1.57 \\
\hline CCL11 & NM_011330 & 0.24 & 0.75 \\
\hline CCL25 & NM_009138 & 0.28 & 0.65 \\
\hline IL3 & NM_010556 & 0.22 & 0.57 \\
\hline IL6ra & NM_010559 & 0.28 & 0.63 \\
\hline TNFSF4 & NM_009452 & 0.22 & 0.54 \\
\hline
\end{tabular}

CTL, control; LPS, lipopolysaccharide; M, 6-MITC; LPS/CTL, $>3$-fold; (M+LPS)/LPS, >2-fold.

representation of the molecular relationships between genes or gene products. Genes or gene products are represented as nodes, and the biological relationship between two nodes is represented as an edge (line). All edges are supported by at least one reference from the literature, from a textbook, or from canonical information stored in the Ingenuity Pathways Knowledge Base. The intensity of the node color indicates the degree of up- (red) or down-regulation (green). Nodes are displayed using various shapes that represent the functional 

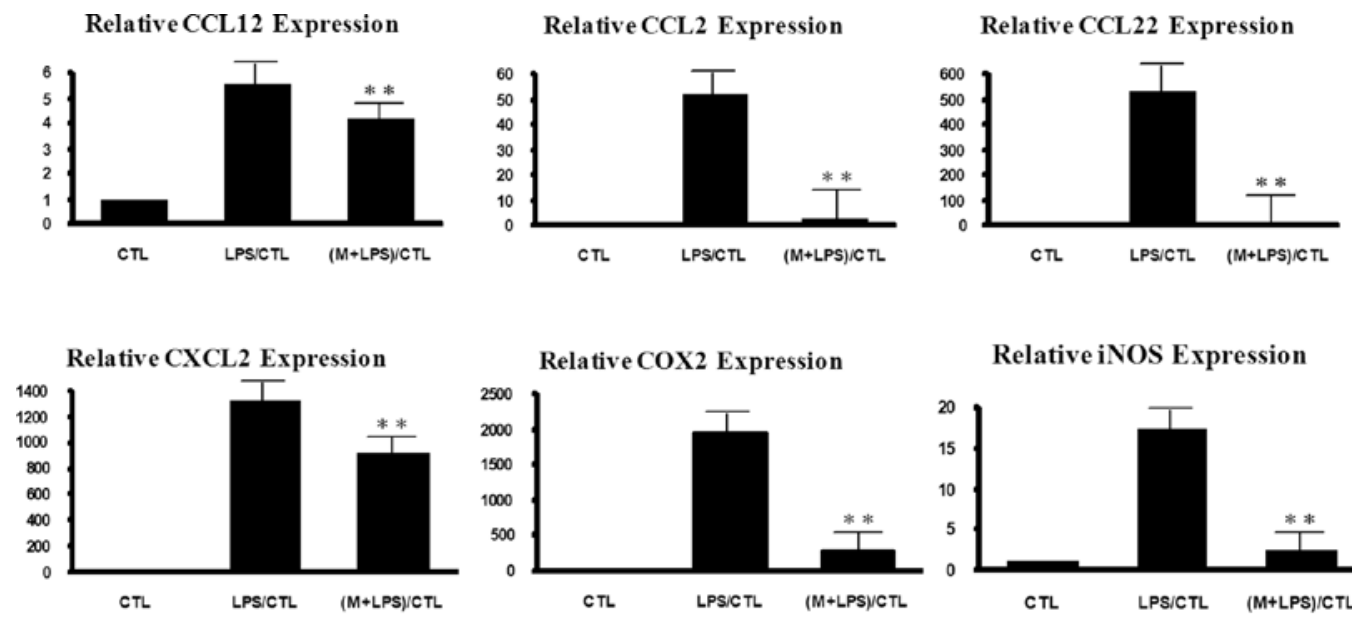

Relative iNOS Expression
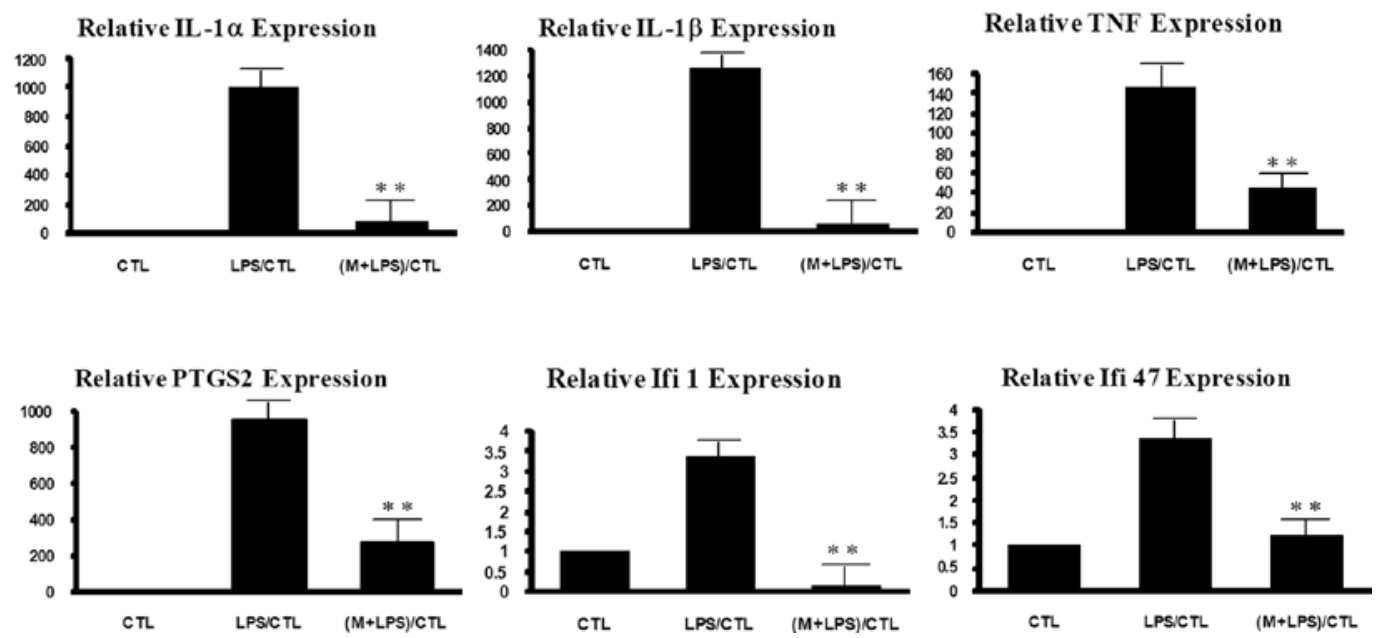

Figure 1. Real-time PCR of various genes identified by the DNA microarray. RAW264.7 cells were pretreated with or without 6-MSITC for 30 min and then exposed to $40 \mathrm{ng} / \mathrm{ml}$ LPS for $6 \mathrm{~h}$. RNA extract and real-time PCR are described in Materials and methods. The primers used were described in previously studies. The result was expressed as the relative expression level. Each value represents the mean $\pm \mathrm{SD}$ of three separate experiments. ${ }^{*} \mathrm{P}<0.05,{ }^{* * *} \mathrm{P}<0.001$ vs. LPS. IL, interleukin; TNF, tumor necrosis factor; PTGS2, prostaglandin-endoperoxide synthase 2; CCL, CC chemokine ligand; CXCL, CXC chemokine (C-X-C motif) ligand; IFI, interferon-inducible protein; iNOS, inducible nitric oxide synthase.

class of the gene product. Edges are displayed with various labels that describe the nature of the relationship between the nodes (e.g., P for phosphorylation, T for transcription).

Statistical analysis. Differences between treated and control cells were analyzed by the Student's t-test. A probability of $\mathrm{P}<0.05$ was considered significant.

\section{Results}

Gene expression profiles. Based on the results of our preexperiments, RAW264.7 cells were treated with or without $8 \mu \mathrm{M}$ 6-MSITC for $30 \mathrm{~min}$ and then exposed to $40 \mathrm{ng} / \mathrm{ml}$ lipopolysaccharide (LPS) for another $6 \mathrm{~h}$. Under this condition, RAW264.7 cells had a favorable response to 6-MSITC without cytotoxicity. Cell mRNA was prepared and processed for hybridization to the mouse oligonucleotide DNA microarray, as described in Materials and methods. Comparing the signals of LPS-treatment with those of the control revealed that a total of 1123 gene signals were changed by $\geq 3$-fold, of which, 406 gene signals were increased and 717 gene signals were decreased by $\geq 3$-fold (Table I). Among the 1123 genes responding to LPS, treatment with 6-MSITC reduced 238 gene signals by $\geq 2$-fold and enhanced 336 gene signals, respectively (Table I). Therefore, 6-MSITC affected $\sim 51 \%$ of the LPS-responsive genes by $\geq 2$-fold. This result suggests that 6-MSITC might be effective in attenuating LPS-induced responses. To validate the accuracy of the microarray data, 6 representative genes with changes in expression of several fold, several ten fold and several hundred fold by LPS were chosen, and their expression levels were detected by real-time PCR with the same RNA. The real-time PCR results exhibited a similar expression pattern with that of the DNA microarray, suggesting the DNA microarray data obtained in the present study is valid (data not shown).

Grouping of genes targeted by 6-MSITC. The genes that showed response to LPS only and LPS plus 6-MITC were classified into biological process, molecular function and signaling pathway by the Gene Ontology software. As shown in Table II, 332 genes with $\geq 3$-fold change by LPS were classified into 35 groups of which 206 genes were regulated by 

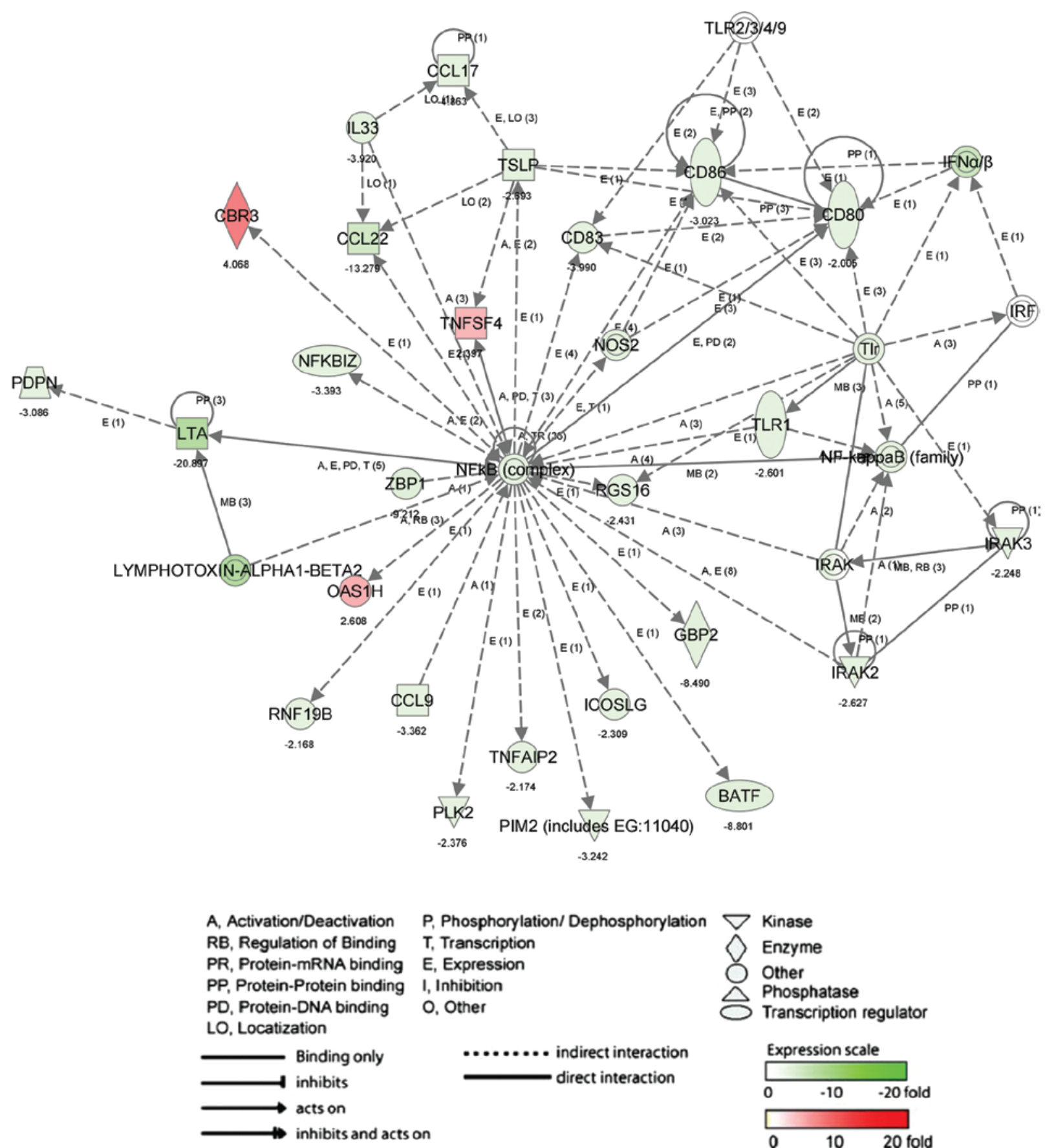

Expression scale

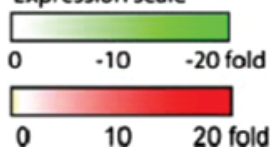

Figure 2. The first integrated network in up- and down-regulated genes by 6-MSITC. The dataset was analyzed by the Ingenuity Pathway analysis software. The node color indicates the expression level of the genes. Nodes and edges are displayed with various shapes and labels that present the functional class of genes and the nature of the relationship between the nodes, respectively.

6-MSITC with $\geq 2$-fold and classified into 30 groups hitting for biological process (81), molecular function (108) and signaling pathway (17) categories. The remaining 11,480 genes were unclassified. The gene groups highly affected by wasabi 6-MSITC were associated with 'inflammatory response, signal transduction, cytokine activities, hydrolase activity, kinase activity, receptor activities, transferase activity, nucleic acid binding and apoptosis' categories.

Profiling of anti-inflammatory effects by 6-MSITC. To investigate the anti-inflammatory effects by 6 -MSITC, we next profiled the genes that are related to inflammatory response, defense, cytokine activity and receptor activity. The changes in gene expression by 6 -MSITC ( $\geq 2$-fold) are partially listed in Table III. The induction of pro-inflammatory genes, including TNF, IL1 $\beta$, IL6, prostaglandin-endoperoxide synthase 2 (PTGS2) and COX-2 by LPS were reduced by 6-MSITC. In addition, the inductions of various $\mathrm{CC}$ and CXC chemokines including chemokine (C-C motif) ligand 17 (CCL17), 22 (CCL22), chemokine (C-X3-C motif) ligand 1 (CX3CL1), chemokine (C-X-C motif) ligand 11 (CXCL11) and 16 (CXCL16) by LPS were suppressed by 6-MSITC. 

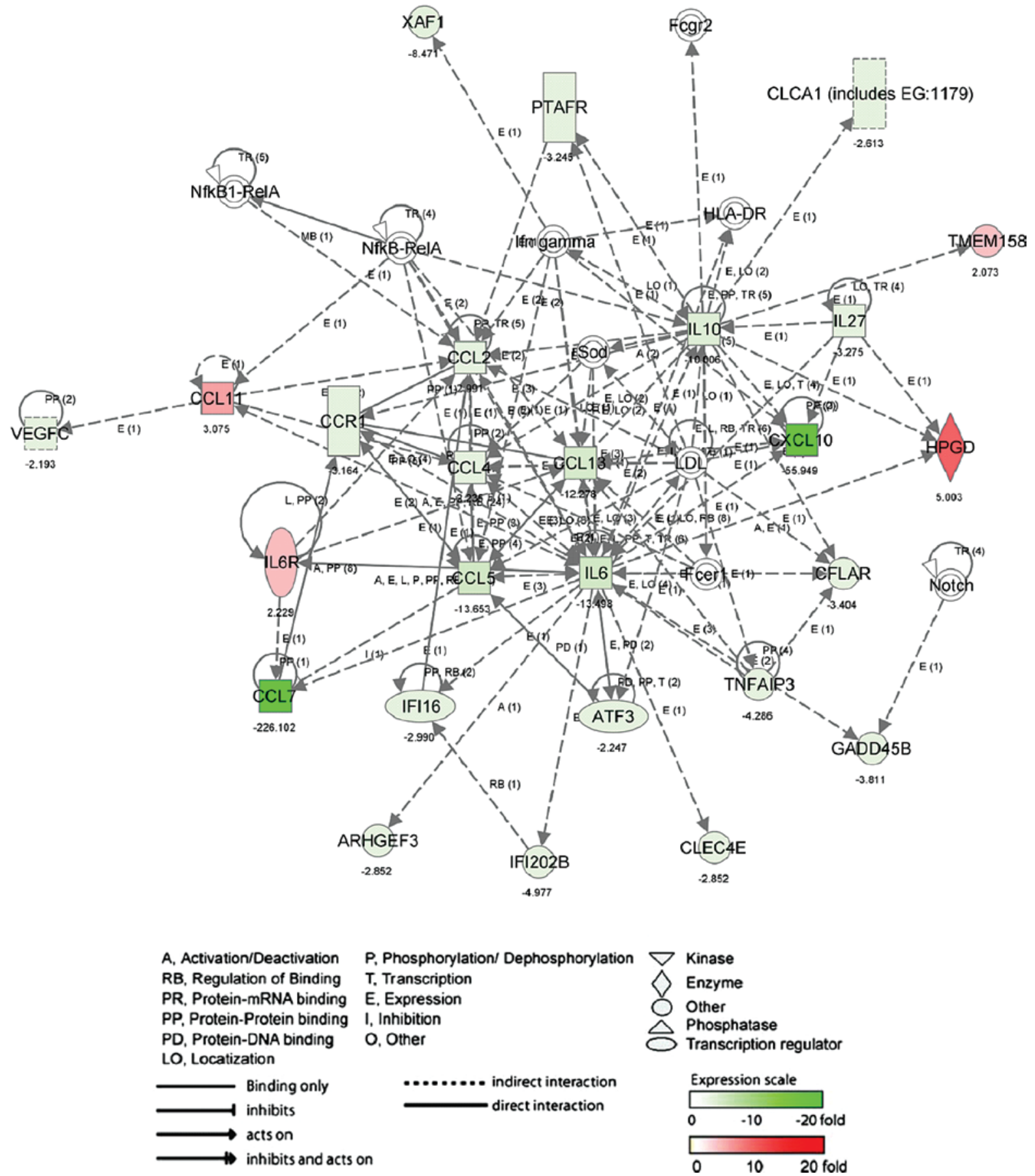

Figure 3. The second integrated network in up- and down-regulated genes by 6-MSITC. The dataset was analyzed by the Ingenuity pathways analysis software. The node color indicates the expression level of the genes. Nodes and edges are displayed with various shapes and labels that present the functional class of genes and the nature of the relationship between the nodes, respectively..

LPS-induced interferon-inducible protein 1 (IFI1) and 47 (IFI47), and interleukin receptor (IL10ra, IL23r and IL4ra) levels were also attenuated by 6-MSITC. On the other hand, LPS decreased the expression levels of a few CC chemokines CCL11 and CCL25), interleukins (IL3) and receptors (IL1ra12, IL8ra, TNFRSF23 and TNFSF4) while 6-MSITC restored them to normal levels.

To confirm the results, the expression levels of IL1 $\beta$, IL6, TNF, COX-2, PTGS2, CCL22, IFI47 and IFI1 were further detected by real-time PCR (Fig. 1). Most showed a similar expression pattern between the microarray and real- time PCR data. For example, the level of LPS-stimulated expression of TNF was reduced by $85 \%$ by 6 -MSITC in the real-time PCR experiment, while the extent of reduction was $68 \%$ in the microarray experiment. The inhibitory effect of 6-MSITC on IFI1 was $60 \%$ in the real-time PCR and $57 \%$ in the microarray experiments. IL1 $\beta$ showed a somewhat lower extent of 6-MSITC effect in the microarray (40\%) than the extent in the real-time PCR experiment (93\%).

Biologically relevant networks and pathways. To determine the biologically relevant networks and pathways of the differ- 
entially expressed genes, pathway analysis was conduced on genes with 2-fold changes upon 6-MSITC treatment, using the Ingenuity Pathway Knowledge Base. The most significant network in up- and down-regulated genes by 6-MSITC (Fig. 2; score, 42 and 26 genes) including inducible T-cell co-stimulator ligand (ICOSLG), tumor necrosis factor (ligand) superfamily member 4 (TNFSF4), CD86 antigen (CD86), nuclear factor of $\kappa$ light polypeptide gene enhancer in B-cell inhibitor $\zeta$ (NFKBIZ), CCL17 and CCL22 was associated with inflammatory response (P-value, 2.46E-4 to $4.47 \mathrm{E}-2$ ) and immune response (P-value, 3.06E-5 to 7.16E-3). The other network (Fig. 3; score, 42 and 26 genes) in up- and down-regulated genes by 6-MSITC, including CCL11, CCL13, CCL2, CCL4, CCL5, CCL7, CCR1, CXCL10, IL6 and IL10 was associated with inflammatory (P-value, 2.27E-9 to 1.15E-3) and immune response (P-value, 6.31E-8 to 6.31E-8).

\section{Discussion}

6-(Methylsulfinyl)hexyl isothiocyanate has been reported to attenuate expression of COX-2 (6) and iNOS (7), and production of prostaglandin E synthase 2 (PGE2) (6) and NO (7), suggesting 6-MSITC may have anti-inflammatory activity. In the present study, we, for the first time, showed the gene expression profiles upon 6-MSITC treaatment in RAW264.7 cells, a cell model system to study inflammation, by genomewide DNA microarray.

Among a total of 22,050 gene probes, LPS treatment at $40 \mathrm{ng} / \mathrm{ml}$ for $6 \mathrm{~h}$ up-regulated signals of 406 gene probes (1.8\% of the total gene probes) and down-regulated signals of 717 gene probes $(3.2 \%$ of the total gene probes) by $\geq 3$-fold. These genes were categorized into 35 groups and hit for biological processes, molecular functions and signaling pathways. The number of genes affected by LPS was fewer than that upon treatment with $1 \mu \mathrm{g} / \mathrm{ml}$ for $6 \mathrm{~h}$ as reported previously (18), suggesting that RAW264 cells responded to LPS in a dose-dependent manner. In our preliminary treatment, we found that a high dose of LPS appeared cytotoxic to RAW246.7 cells; we thus treated the cells with $40 \mathrm{ng} / \mathrm{ml}$ LPS in the present study to mimic an inflammatory response under normal conditions.

The number of genes affected by 6-MSITC treatment consisted of $58 \%$ of genes down-regulated by LPS and $47 \%$ of genes up-regulated by LPS. Analysis of the genes targeted by 6 -MSITC revealed that a number of inflammation and defense-related genes were affected. The up-regulation of pro-inflammatory genes, such as TNF, IL1 $\beta$, IL6, PTGS and COX-2 by LPS has been suggested to be a major factor for the inflammatory effects observed in LPS-activated macrophages $(20,21)$, and 6-MSITC appeared to attenuate their expression. In addition, 6-MSITC reduced the expression of interferon-inducible genes (IFI1 and IFI47). These factors are documented to be involved in interferon-mediated immunity and cell proliferation and differentiation (22). The inductions of interleukin receptors (IL10ra, IL23r and IL4ra) by LPS were also suppressed by 6-MSITC. These results suggest that 6-MSITC inhibition of the expression of various pro-inflammatory genes may explain its anti-inflammatory effects. On the other hand, 6-MSITC also restored the expression levels of LPS-reduced CC chemokines (CCL11 and CCL25), interleukins (IL3) and receptors (IL1ra12, IL8ra, TNFRSF23 and TNFRSF4) to control levels. The data suggest that wasabi 6-MSITC might not only attenuate the expression of certain pro-inflammatory genes induced by LPS but also restore the expression level of anti-inflammatory genes reduced by LPS although detailed information must be obtained through further studies.

In summary, our DNA microarray data, for the first time, revealed gene expression profiling of wasabi 6-MSITC in an inflammatory cell model, RAW264.7. 6-MSITC may target immune and inflammation-related genes including chemokines, interleukins and interferons to exert its anti-inflammatory function. These data provide a basis for understanding the molecular mechanisms of the anti-inflammatory effects of wasabi.

\section{Acknowledgements}

This study was supported, in part, through a fund of the Frontier Science Research Center of Kagoshima University to De-Xing Hou.

\section{References}

1. Isshiki K and Tokuoka K: Allyl isothiocyanate and wholesomeness of food. Jpn J Food Microbiol 12: 1-6, 1993.

2. Kumagai H, Kashima N, Seki T, Sakurai H, Ishii K and Ariga T: Analysis of components in essential oil of upland wasabi and their inhibitory effects on platelet aggregation. Biosci Biotech Biochem 58: 2131-2135, 1994.

3. Tanida N, Kawaura A, Takahashi A, Sawada K and Shimoyama T: Suppressive effect of wasabi (pungent Japanese spice) on gastric carcinogenesis induced by MNNG in rats. Nutr Cancer 16: 53-58, 1991.

4. Ono H, Adach K, Fuke Y and Shinohara K: Purification and structural analysis of substances in wasabi (Eutrema wasabi Maxim.) that suppress the growth of MKN-28 human stomach cancer cells. J Jpn Food Sci Technol 43: 1092-1097, 1996.

5. Morimitsu Y, Nakagawa Y, Hayashi K, Fujii H, Kumagai T and Nakamura Y: A sulforaphane analogue that potently activates the Nrf2-dependent detoxification pathway. J Biol Chem 277: 3456-3463, 2002

6. Uto T, Fujii M and Hou DX: Inhibition of lipopolysaccharideinduced cyclooxygenase- 2 transcription by 6 -(methylsulfinyl) hexyl isothiocyanate, a chemopreventive compound from Wasabia japonica (Miq.) Matsumura, in mouse macrophages. Biochem Pharmacol 70: 1772-1784, 2005.

7. Uto T, Fujii M and Hou DX: 6-(Methylsulfinyl)hexyl isothiocyanate suppresses inducible nitric oxide synthase expression through the inhibition of Janus kinase 2-mediated JNK pathway in lipopolysaccharide-activated murine macrophages. Biochem Pharmacol 70: 1211-1221, 2005.

8. Baggiolini M: Chemokines and leukocyte traffic. Nature 392: 565-568, 1998.

9. Akira S, Takeda $\mathrm{K}$ and Kaisho T: Toll-like receptors: critical proteins linking innate and acquired immunity. Nat Immunol 2: 675-680, 2001.

10. Erridge C, Bennett-Guerrero E and Poxton IR: Structure and function of lipopolysaccharides. Microbes Infect 4: 837-851, 2002.

11. Shimazu R, Akashi S, Ogata H, Nagai Y, Fukudome K, Miyake K and Kimoto M: MD-2, a molecule that confers lipopolysaccharide responsiveness on Toll-like receptor 4. J Exp Med 189: 1777-1782, 1999.

12. Poltorak A, He X, Smirnova I, Liu MY, van Huffel C, Du X, Birdwell D, Alejos E, Silva M, Galanos C, Freudenberg M, Ricciardi-Castagnoli P, Layton B and Beutler B: Defective LPS signaling in $\mathrm{C} 3 \mathrm{H} / \mathrm{HeJ}$ and $\mathrm{C} 57 \mathrm{BL} / 10 \mathrm{ScCr}$ mice: mutations in Tlr4 gene. Science 282: 2085-2088, 1998.

13. Beutler B, Jiang Z, Georgel P, Crozat K, Croker B and Rutschmann S: Genetic analysis of host resistance: toll-like receptor signaling and immunity at large. Annu Rev Immunol 24: 353-389, 2006. 
14. O'Neill LA and Bowie AG: The family of five: TIR-domaincontaining adaptors in Toll-like receptor signalling. Nat Rev Immunol 7: 353-364, 2007.

15. Akira S, Uematsu S and Takeuchi O: Pathogen recognition and innate immunity. Cell 124: 783-801, 2006.

16. Chen JH, Uto T, Tanigawa S, Kumamoto T, Fujii M and Hou DX Expression profiling of genes targeted by bilberry (Vaccinium myrtillus) in macrophages through DNA microarray. Nutr Cancer 60: 43-50, 2008.

17. Tao JY, Zhao L, Huang ZJ, Zhang XY, Zhang SL, Zhang QG, Fei-Xiao, Zhang BH, Feng QL and Zheng GH: Anti-inflammatory effects of ethanol extract from Kummerowia striata (Thunb.) Schindl on LPS-stimulated RAW 264.7 cell. Inflammation 31: 154-166, 2008

18. Beaty SR, Rose CE Jr and Sung SS: Diverse and potent chemokine production by lung CD $11 \mathrm{~b}$ high dendritic cells in homeostasis and in allergic lung inflammation. J Immunol 178 1882-1895, 2007.
19. Huang H, Chang EJ, Lee Y, Kim JS, Kang SS and Kim HH: A genome-wide microarray analysis reveals anti-inflammatory target genes of paeonol in macrophages. Inflamm Res 26: 189-198, 2008.

20. Alcorn JF and Wright JR: Surfactant protein A inhibits alveolar macrophage cytokine production by CD14-independent pathway. Am J Physiol Lung Cell Mol Physiol 286: 129-136, 2004.

21. Fassbender K, Mielke O, Bertsch T, Muehlhauser F, Hennnerici M, Kurimoto $\mathrm{M}$ and Rossol S: Interferon-gammainducing factor (IL-18) and interferon-gamma in inflammatory CNS diseases. Neurology 53: 1104-1106, 1999.

22. Asefa B, Klarmann KD, Copeland NG, Gilbert DJ, Jenkins NA and Keller JR: The interferon-inducible p200 family of proteins: a perspective on their roles in cell cycle regulation and differentiation. Blood Cells Mol Dis 32: 155-167, 2004. 